\title{
The relationship between non-verbal intelligence and mathematical achievement in high school students
}

\author{
Tatiana Tikhomirova ${ }^{1, *}$, Irina Voronina $^{1}$, Julia Marakshina ${ }^{1}$, Evgeny Nikulchev $^{2}$, Isabella Ayrapetyan $^{1}$ and $_{\text {Tamara Malykh }}{ }^{1}$ \\ ${ }^{1}$ Psychological Institute of Russian Academy of Education, 125009, Moscow, Russia \\ ${ }^{2}$ Moscow Technological Institute, 199334, Moscow, Russia
}

\begin{abstract}
The current study focuses on the relationship between non-verbal intelligence and math performance at school measured with a number of methods such as teachers' evaluation, computerized math tasks and standardized state exams for high school students. The study involved 174 high school students in the last obligatory year of formal education at school in Russia (mean age $=15.77$ years, $\mathrm{SD}=0.47,44.8 \%$ males) from secondary public school in the Moscow region. It was shown that non-verbal intelligence is a significant predictor of different measures of math performance at high school age. At the same time, we found that the contribution of non-verbal intelligence varies for different measures of math performance: from high values for of the Basic State Exam in Math scores to lower values for teachers' quarterly ratings. Correlation between math performance measured by teachers' ratings, computerized math tasks and standardized state exams was found to be moderate. It is possible that different types and configurations of math tasks require different types of cognitive, motivational and emotional resources at high school age.
\end{abstract}

\section{Introduction}

Individual differences in academic performance are predominantly associated with the efficiency of cognitive processes and intelligence in particular [1-3]. A recent comparative study shows that prognostic validity is much higher for intelligence than for personality at school age [4]. In the majority of studies intellectual characteristics were measured with tests for non-verbal intelligence. Non-verbal intelligence in this case was defined as the ability to solve tasks based on non-verbal material [2].

Meta-analyses show that correlation rates between non-verbal intelligence and academic performance at school range from 0.40 to $0.63[1,5,6]$. Correlation varies in accordance with the method that was used to measure intelligence: it tends to be higher for the latent ' $\mathrm{g}$ ' factor that sometimes correlates with performance (up to 0.81 ) [1].

However, the detailed pattern of correlation at different school periods remains unclear. For example, in Estonia intelligence plays the most important role in academic performance during the first school year $(\mathrm{r}=0.54, p<0.01)$, while for high school the correlation is lower $(\mathrm{r}=0.32, p<0.01)$ [4].

The changes in the role of intelligence in academic performance can be associated with unique developmental trajectories of intelligence as well as academic performance itself. Thus, intelligence develops non-uniformly with a pronounced tempo in some children and less pronounced in others [7]. The diversity of the trajectories relevant to education is also associated with the variability in socio-economic status during different school periods [7-9]. Academic performance is generally lower at high school age: 4th grade students show higher scores on international ratings (TIMMS, PISA) than 9th grade students.

Math performance is one of the most studied phenomena in the context of the relationship between academic performance and intelligence $[1,6,10]$. Academic performance measures are based on teachers' grades for different school subjects. However, different measures of academic performance show different association with cognitive characteristics [11].

The present study focuses on the relationship between non-verbal intelligence and math performance at school measured with a number of methods such as teachers' evaluation, computerized math tasks and standardized state exams for high school students.

\section{Methods}

\subsection{Participants}

The current study involved 174 high school students in 9th grades (mean age $=15.77$ years, $\mathrm{SD}=0.47$ ) from secondary public school in the Moscow region (44.8\% male). 9th grade is the last obligatory year of formal education at school in Russia. All 9th grade students have to pass a state exam at the end of the school year.

Corresponding author: tikho@mail.ru 


\subsection{Measures}

\subsubsection{Intelligence}

Non-verbal intelligence was measured with the 'Raven Progressive Matrices' test (RPM) [12]. It consists of 60 tasks grouped in 5 series. In series A, participants have to complement the missing part of an image. In series B they are asked to find correspondence between pairs. In series $\mathrm{C}$ the tasks are related to geometrical principles in figure changes. In series D participants have to find the structure in shuffling of figures. Series $\mathrm{E}$ requires the ability to analyze figures and add it to the missing parts. Each correct answer was counted as 1 score. Total scores were calculated.

\subsubsection{Mathematical achievement}

We used total math score of the Basic State Exam (BSE) in Math as the first measure of math performance. BSE is the state exam at the end of obligatory education. It monitors students' knowledge and can be used for assignment to field-specific class or entry to vocational college. Math and Russian BSEs are obligatory for all students. Math BSE includes 3 modules: 1) "Algebra", 2) "Geometry", 3) "Applied Maths". Each module consists of multiple choice tests and higher-level tasks that require explicated solution and answer. Students get raw scores according to the number of correct answers, the scores are then converted to a five-point scale. In the present study we used math BSE raw scores.

Secondly, math teachers' quarter grades were used as an expert evaluation of success in learning Maths. We analyzed the arithmetic average of teachers' ratings on Maths for more subtle differentiation of expert ratings.

Thirdly, we used a computerized math test consisting of math and logical tasks and equations [13]. The test includes 18 tasks organized in 3 levels composed of 6 items. Each level is further subdivided into 3 sub-levels of increasing difficulty. Level 1 corresponds to the easiest level. The first two tasks from the first sub-level 1.1 are the easiest, followed by 1.2 and 1.3 and so on. The administration of the test follows a branching system: the starting point is the same for all participants but the order of tasks is determined by their abilities. Participants start at level 2 (with the task 2.1 - level 2, first question-medium difficulty) and are awarded one point for each correct answer. If both questions in one sub-level are answered correctly, participants progress to the next level and the questions preceding the sub-level are credited; one point is awarded for each credited question. If one question of the sub-level is answered incorrectly, the program would present questions of the preceding (easier) sub-levels. The task is interrupted when two questions in a row are answered incorrectly.

\section{Results and discussion}

We analyzed 3 math performance measures - average of the teachers' quarter grades, computerized math test scores and Math BSE scores.
Table 1 shows means and standard deviations (in brackets) for all math performance measures and Raven Progressive Matrices (RPM) total scores.

Table 1. Descriptive statistics for measures of math performance and intelligence.

\begin{tabular}{|c|c|}
\hline & Mean (SD) \\
\hline RPM & $48.35(6.4)$ \\
\hline $\begin{array}{c}\text { Teachers' } \\
\text { rating score }\end{array}$ & $3.82(0.6)$ \\
\hline BSE & $18.79(5.5)$ \\
\hline Math test & $11.47(3.6)$ \\
\hline
\end{tabular}

RPM scores theoretical maximum is 60 . Teachers' rating score is an average of quarter grades and ranges from 2 to 5. Math BSE scores are presented as raw scores. Computerized math test scores are presented as a number of correct answers out of 18 test tasks.

\subsection{Correlation between different variables of Math achievement}

We calculated correlations between teachers' ratings, BSE scores and computerized test scores.

Table 2 shows Spearman correlation coefficients between 3 measures $(p<0.01)$.

Table 2. Correlations between different variables of Math achievement.

\begin{tabular}{|c|c|c|c|}
\hline & $\begin{array}{c}\text { Teachers' } \\
\text { rating score }\end{array}$ & BSE & Math test \\
\hline $\begin{array}{c}\text { Teachers' } \\
\text { rating score }\end{array}$ & 1.00 & & \\
\hline BSE & 0.62 & 1.00 & \\
\hline Math test & 0.35 & 0.48 & 1.00 \\
\hline
\end{tabular}

The highest correlation was found between teachers' ratings and BSE scores $(\mathrm{r}=0.62, p<0.01)$. Computerized test scores moderately correlated with teachers' ratings $(\mathrm{r}=0.35, p<0.01)$ and BSE raw scores $(\mathrm{r}=0.48, p<0.01)$. Similar results were previously found for 11th grade students (e.g., [11]).

\subsection{Correlation between RPM' scores and Math achievement}

Table 3 shows Spearman correlation coefficients between different measures of math performance and RPM scores.

Correlation coefficient was highest for non-verbal intelligence and BSE raw scores $(\mathrm{r}=0.51, p<0.01)$. Non-verbal intelligence was moderately associated with computerized test scores and teachers' ratings $(0.32<\mathrm{r}<0.37)$. 
Table 3. Correlations between RPM' scores and different variables of Math achievement.

\begin{tabular}{|c|c|}
\hline & RPM scores \\
\hline $\begin{array}{c}\text { Teacher' } \\
\text { rating score }\end{array}$ & 0.32 \\
\hline BSE & 0.51 \\
\hline Math test & 0.37 \\
\hline
\end{tabular}

The results regarding the relationship between intelligence scores and the computerized test scores are in line with the studies: the correlation between the computerized test and intelligence on a Russian sample reaches 0.30 [14]. However, in this study no association between non-verbal intelligence and BSE scores was found [14]. This discrepancy can point to ongoing development of the BSE by the Ministry of education and science of the Russian Federation.

\subsection{Regression analyses}

We performed regression analyses for each math performance measure and non-verbal intelligence. The number of correct answers in RPM was used as a predictor.

Table 4 shows the summary of regression analyses.

Table 4. Correlations between different variables of Math achievement.

\begin{tabular}{|c|c|c|c|c|}
\hline & $\beta$ & B & $\begin{array}{c}\text { Standard } \\
\text { error } \\
\text { of B }\end{array}$ & $\begin{array}{c}95 \% \\
\text { conf. } \\
\text { interval }\end{array}$ \\
\hline $\begin{array}{c}\text { Teacher' } \\
\text { rating score }\end{array}$ & 0.36 & 0.04 & 0.01 & $0.01-0.06$ \\
\hline BSE & 0.54 & 0.43 & 0.09 & $0.25-0.60$ \\
\hline Math test & 0.39 & 0.23 & 0.07 & $0.08-0.37$ \\
\hline
\end{tabular}

Regression analyses showed that the biggest effect of intelligence on variance of math performance was for $\mathrm{BSE}$ results (corrected $\mathrm{R}^{2}=0.29, \mathrm{~F}=25.43, p<0.001$ ). The regression model for teachers' ratings explained only $12 \%$ of the variance $(\mathrm{F}=9.41, p<0.01)$. The regression model for the computerized test explained $14 \%$ of the variance $(\mathrm{F}=10.12, p<0.01)$.

The study showed that the role of non-verbal intelligence is significant for individual differences regardless of math performance measure. Our results are in line with other studies that show the major role of non-verbal intelligence in academic performance for various subjects $[1,15]$. Moreover, intelligence plays a central role in the relationship between cognitive functions and academic performance [2].

At the same time, the effect of non-verbal intelligence can differ for different types of math performance measures: from high values for BSE scores ( $29 \%$ of its variance) to lower values for teachers' quarterly ratings ( $12 \%$ of the variance). Indeed, teachers' ratings can be more influenced by subjective factors and personality of the teacher $[8,16]$. On the other side, oral presentation rated by teachers may involve other resources than the computerized test or exam tasks [17].

\section{Conclusions}

The present study investigated the relationship between non-verbal intelligence and math performance at school measured with different methods: teachers' evaluation, computerized math tasks and standardized state examination results.

Correlation and regression analyses showed that nonverbal intelligence is a significant predictor of different measures of math performance at high school age. The contribution of non-verbal intelligence varies for different measures of math performance.

Correlation between math performance measured by teachers' ratings, computerized math tasks and standardized state exams was found to be moderate. It is possible that different types and configurations of math tasks require different types of cognitive, motivational and emotional resources.

\section{References}

1. I.J. Deary, S. Strand, P. Smith, C. Fernandez, Intelligence, 35, 13 (2007)

2. H. Rindermann, A.C. Neubauer, Intelligence, 32, 573 (2004)

3. R.J. Sternberg, E.L. Grigorenko and D.A. Bundy, Merrill-Palmer Quarterly, 47, 1 (2001)

4. K. Laidra, H. Pullmann, J. Allik, Personality and Individual Differences, 42, 441 (2007)

5. C. Jencks. Who gets ahead? The determinants of economic success in America (Basic Books, 1979)

6. D. Luo, L.A. Thompson and D.K. Detterman, Intelligence, 34, 79 (2006)

7. S. Von Stumm and R. Plomin, Intelligence, 48, 30 (2015)

8. T.N. Tikhomirova, A.D. Modyaev, N.M. Leonova, S.B. Malykh, Psikhologicheskii Zhurnal [Psychological journal], 36, 43 (2015)

9. E.M. Tucker-Drob and D.A. Briley, Psychological Bulletin, 140, 949 (2014)

10. T.N. Tikhomirova, Psikhologicheskii Zhurnal [Psychological journal], 32, 30 (2011)

11. T.N. Tikhomirova, S.B. Malykh, M.G. Tosto, Y.V. Kovas, Psikhologicheskii Zhurnal [Psychological journal], 35, 41 (2014)

12. J. Raven, Cognitive Psychology, 41, 1 (2000)

13. M.G. Tosto, T. Tikhomirova, E. Galajinsky, K. Akimova, Y. Kovas, Procedia - Social and Behavioral Sciences, 86, 423 (2013)

14. V.I. Morosanova, T.G. Fomina, Y.V. Kovas, Psikhologicheskie Issledovaniya, 7, 11 (2014)

15. G.E. Taub, T.Z. Keith, R.G. Floyd, K.S. McGrew, School Psychology Quarterly, 53, 187 (2008)

16. E. Hejazi, M.G. Lavasani, F. Mazarei, Procedia Social and Behavioral Sciences, 15, 646 (2011)

17. T.N. Tikhomirova, Y.V. Kovas, Psikhologicheskii Zhurnal [Psychological journal], 34, 63 (2013) 